\title{
MOTIVACIÓN Y CALIDAD DOCENTE EN LA UNIVERSIDAD
}

Silvero M., Marta (2006). Motivación y calidad docente en la universidad. Navarra, España; Eunsa, 290 págs.

En esta publicación, Marta Silvero Miramón, doctora en Educación de la Universidad de Navarra, desarrolla un estudio descriptivo y crítico del concepto de calidad docente en la universidad, así como de los diferentes enfoques con los que se ha pretendido evaluarla.

La autora presenta la motivación docente del profesor universitario como un indicador de esa calidad y realiza un estudio de la fundamentación teórica de este constructo. Se señala así la multidimensionalidad del concepto, de acuerdo con tres parámetros principales sobre los que elaborar un análisis global e integrador: elementos de valor (metas), elementos de control (expectativas y atribuciones) y elementos afectivos (emociones y reacciones psicopatológicas adversas).

Asimismo, presenta una revisión de los principales instrumentos para evaluar la motivación docente, dejando evidencia de la escasez de proyectos e investigaciones en este ámbito. Se concluye la necesidad de profundizar en el estudio de esta motivación y, en consecuencia, de establecer la fundamentación teórica y la construcción de instrumentos fiables y válidos que permitan evaluarla.

Esta obra profundiza en los elementos que componen la motivación docente e influyen en ella, en la búsqueda de un concepto unitario que permita establecer las cuestiones fundamentales que pueden afectar este aspecto del desempeño del profesor universitario y la calidad de su trabajo. Pretende ser, por tanto, una breve y sencilla 
aportación para la formación de éste, que sirva para su propio estudio y reflexión.

\author{
Ernesto Pérez Arocas \\ Grupo interdisciplinario \\ Asesoría y selección bibliográfica \\ libreria@prosaypolitica.cl
}

